\title{
A Measurement System for Time Constant of Thermocouple Sensor Based on High Temperature Furnace
}

\author{
Yanfeng $\mathrm{Li}^{1}{ }^{1}$, Zhijie Zhang ${ }^{1,2, *}$, Xiaojian Hao ${ }^{1,2}$ and Wuliang Yin ${ }^{1,3}$ \\ 1 School of Instrument and Electronics, North University of China, Taiyuan 030051, Shanxi, China; \\ liyanfeng2013@126.com (Y.L.); haoxiaojian@nuc.edu.cn (X.H.); wuliang.yin@manchester.ac.uk (W.Y.) \\ 2 Key Laboratory of Instrumentation Science \& Dynamic Measurement (North University of China), Ministry \\ of Education, Taiyuan 030051, Shanxi, China \\ 3 School of Electrical and Electronic Engineering, University of Manchester, Manchester M13 9PL, UK \\ * Correspondence: zhangzhijie@nuc.edu.cn
}

Received: 25 October 2018; Accepted: 10 December 2018; Published: 12 December 2018

\begin{abstract}
In dynamic temperature measurement, thermocouple sensors are widely used, and their dynamic characteristics directly affect the accuracy of the test results. So before applying thermocouple sensors to dynamic temperature measurement, their dynamic characteristics should be obtained, and their dynamic performance parameters should be analyzed. The time constant is the most important dynamic parameter, which reflects the response speed of a thermocouple sensor. Therefore, it is necessary to measure the time constant. The time constant is closely related to the heat transfer mode, so the heat transfer environment of the time constant measurement system should be similar to the application environment of thermocouple sensor. When using the thermocouple to measure the temperature in various kilns, the heat transfer is mainly through the radiative mode, and existing equipment, such as constant temperature water/oil tank, shock wave tube and other devices, cannot be used to measure the time constant to reflect scenarios in actual measurement applications. Therefore, this paper proposed a new method to measure the time constant of the thermocouple by improved high temperature furnace. In the system, the high temperature furnace was used to generate the stable temperature field, and the fast feed device was used to insert the thermocouple into the high temperature furnace and generates the ramp temperature excitation. The temperature can reach $1500^{\circ} \mathrm{C}$ in the furnace, and the temperature error in uniform temperature field is $\pm 1{ }^{\circ} \mathrm{C}$. Finally, the time constant of a K-type thermocouple was measured, and the uncertainty of the measurement result was analyzed.
\end{abstract}

Keywords: thermocouple; time constant; high temperature furnace; ramp excitation signal

\section{Introduction}

Thermocouple sensor is widely used in dynamic temperature measurement in harsh environment because of its simple structure, low cost, and strong robustness. The temperature measurement principle of the thermocouple is based on the heat balance, that is, the thermocouple must contact the object to be measured and achieve the heat balance. The existence of the heat transfer process causes the thermocouple to have thermal inertia, which affects the dynamic performance of the thermocouple. The time constant is the most important dynamic parameter and reflects the response speed of temperature sensor. It refers to the time for the system's step response to reach $63.2 \%$ of its final temperature value. Before applying the thermocouple to dynamic temperature measurement, its time constant should be measured first. The time constant of the thermocouple is not only related to the material and structure of the sensor itself, but also to the object to be measured and the heat 
transfer mode. At present, there are many kinds of measurement methods and devices of time constant, such as constant temperature water/oil tank, hot wind tunnel, shock tube, laser, and so on.

Stable temperature fields in water flow and airflow environments are generated by constant temperature water/oil tank and hot wind tunnel respectively. The thermocouple is inserted into the stable flow field rapidly, and the thermocouple is excited by step temperature. The time constant is obtained by the thermocouple response. Xiong J. and Wang X.N. [1,2] measured the response time and delay time of the thermocouple by constant temperature water/oil tank, and the dynamic error was corrected. Zhao S.A. [3] developed a hot wind tunnel with the temperature range from $1000{ }^{\circ} \mathrm{C}$ to $1700{ }^{\circ} \mathrm{C}$, and the step response of the thermocouple was obtained. Shock tube is used to generate step pressure, which is usually used for dynamic calibration of pressure sensors. After breaking the film, the gas in the high pressure chamber compresses the gas in the low pressure chamber to produce the shock wave. The step pressure is generated on the pressure sensor by the shock wave and used to excite the pressure sensor. At the same time, due to the gas compression, there is also a temperature step behind the shock wave, which can be used to excite the thermocouple. Meng X.F. et al. $[4,5]$ modified the shock tube and constructed a new dynamic calibration system for the thermocouple, which can generate a stable temperature excitation lasting for a long time. Garinei A. et al. [6] heated the thermocouple to a certain temperature by laser, then turned off the laser, and the thermocouple was excited by a negative temperature step. Serio B. and Hao X.J. et al. [7-11] used high-power laser to generate a rapid temperature rise on the thermocouple surface and obtained the time constant. In addition, there are other methods for dynamic excitation and calibration of thermocouple [12-15].

In the measurement methods and systems for time constant, how to produce stable temperature field and step excitation is the main research content when the system is established. In the above measurement methods, the measurement systems under water flow and air flow environments were constructed for different heat transfer environments. The constant temperature water/oil tank can provide uniform and stable temperature field, but the temperature is low. Hot wind tunnels and shock tubes can produce higher air temperature, but the temperature field is less uniform. In some industrial production, various types of kilns are widely used, such as roller kilns in metallurgical industry, kilns in ceramic industry and cement rotary kilns in construction industry. The measurement of dynamic temperature in kilns is of great significance for product process control and energy consumption reduction. At present, thermocouple sensors are commonly used to measure the temperature, and the response speed directly affects the accuracy of dynamic temperature measurement in furnace. Time constants of thermocouple sensors should be measured. Because the heat transfer mode of the thermocouple in furnace is mainly radiative heat transfer, time constant measurement systems under water flow or gas flow environment cannot be applied to the time constant measurement. Therefore, the application of a high temperature furnace to produce stable temperature field was proposed in this paper.

A new measurement system for the time constant was constructed based on high temperature furnace [16]. Different from convective heat transfer mode in constant temperature water/oil tank, hot wind tunnel and shock tube, radiative heat transfer mode is the main heat transfer mode of the thermocouple in high temperature furnace. In the system, the high temperature furnace can produce uniform temperature field, the temperature can reach $1500{ }^{\circ} \mathrm{C}$, and the temperature error in the uniform temperature field is $\pm 1{ }^{\circ} \mathrm{C}$. When the temperature of the uniform temperature zone is within $300-700^{\circ} \mathrm{C}$, the temperature profile from the furnace mouth to uniform temperature zone is linear. The fast feed device inserts the thermocouple quickly into the uniform temperature field and generates the ramp temperature excitation. The speed of the thermocouple inserted into the high temperature furnace can be set by fast feed device. The time constant of a K-type thermocouple was measured, and the uncertainty of the measurement result was analyzed. 


\section{Analysis of Ramp Excitation Signal}

Because of the wide spectrum, the step signal is usually used as the excitation signal for the dynamic calibration of sensors. The rise time of step signal from initial value to stable value is $0 \mathrm{~s}$. However, in the actual calibration experiment, it is not feasible to generate step temperature excitation with rise time of $0 \mathrm{~s}$. The excitation signal is generally an approximate step signal with a certain rise time, which is called ramp signal. Assuming that the rise time of ramp signal is $r$, and the ramp signal can be expressed as

$$
u^{*}(t)= \begin{cases}t / r, & t<r \\ 1, & t \geq r\end{cases}
$$

The Laplace transform of Equation (1) is

$$
U^{*}(s)=\frac{\left(1-e^{-r s}\right)}{r s^{2}} .
$$

The frequency response function is

$$
\left|U^{*}(j \omega)\right|=\frac{2}{r \omega^{2}}\left|\sin \frac{r \omega}{2}\right| .
$$

The ramp signal and its amplitude spectrum are shown in Figure 1. It can be seen from the figure that the larger the rise time of the ramp excitation signal, the smaller the width of the first main lobe of its spectrum. When the first main lobe is used for dynamic calibration, the working frequency of the thermocouple which can be calibrated is narrower. In time domain, the larger the rise time of the ramp excitation signal, the larger the time constant of the thermocouple which can be calibrated. In the existing measurement system of time constant of the thermocouple, such as hot wind tunnel and shock tube, the temperature excitation signal is generally a ramp signal, and the rise time of the slope signal is often unknown or difficult to measure. In time constant measurement, the time constant is obtained from the response signal. If the response signal is considered as the response of step excitation, but it is actually the response of ramp signal, the measurement error of time constant will occur.
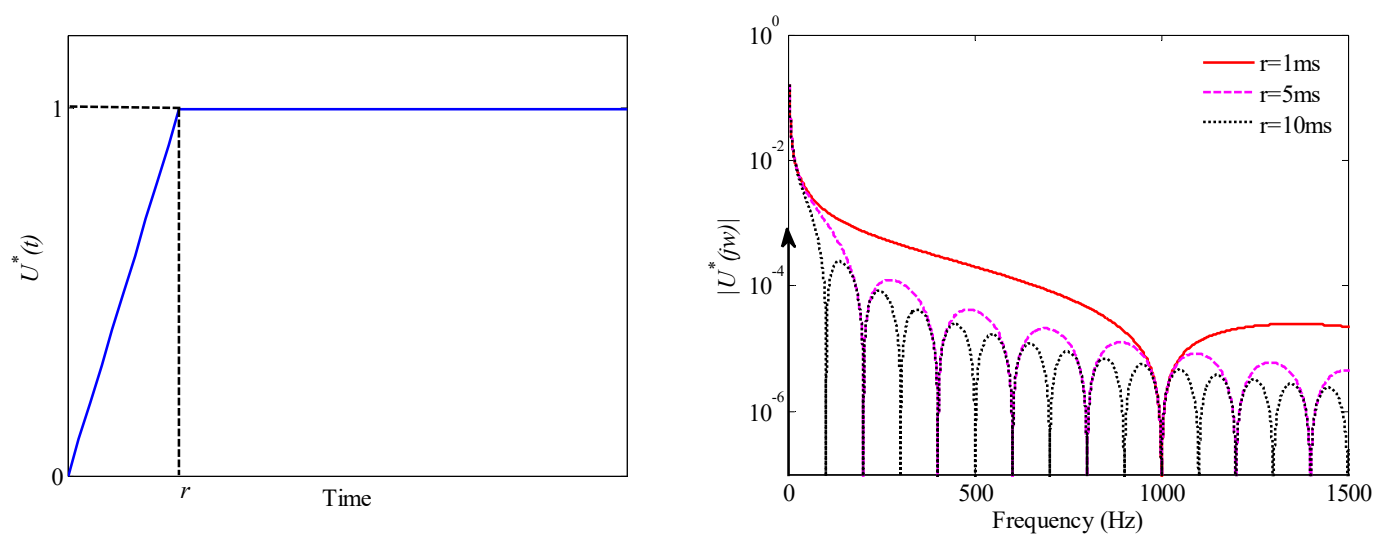

Figure 1. Ramp signal and its amplitude spectrum.

In order to study the effect of ramp excitation signals with different rise times on time constant measurement, assuming that the time constant of the thermocouple is $1 \mathrm{~s}$ and the thermocouple model is a first-order lag model with unity gain, the ramp signals with different rise times are used as excitation signals, the time constants are obtained according to the response curves. The results are shown in Table 1. As can be seen from the table, if the measurement error of the time constant is less than $5 \%$, the rise time of the ramp excitation signal should be less than $10 \%$ of the time constant. When the time constant of the thermocouple is $10 \mathrm{~s}$ and $15 \mathrm{~s}$, the same simulation experiments were carried out, and the results are the same as that in Table 1. Therefore, the relative error of the measurement 
value of time constant measurement is only related to the ratio of increasing time of ramp signal to time constant of the thermocouple.

Table 1. Estimation error of time constant when ramp signal is used as excitation

\begin{tabular}{cccc}
\hline Rise Time $\boldsymbol{r}(\mathbf{m s})$ & $\begin{array}{c}\text { Rise Time } \boldsymbol{r} \text { /Time } \\
\text { Constant } \boldsymbol{\tau} \mathbf{( \% )}\end{array}$ & $\begin{array}{c}\text { Estimate of Time } \\
\text { Constant (ms) }\end{array}$ & Relative Error (\%) \\
\hline 20 & 2 & 1010 & 1.0 \\
50 & 5 & 1025 & 2.5 \\
100 & 10 & 1050 & 5.0 \\
150 & 15 & 1075 & 7.5 \\
200 & 20 & 1100 & 10 \\
\hline
\end{tabular}

\section{Measurement System for Time Constant Based on High Temperature Furnace}

The measurement procedure of time constant of the thermocouple mainly includes: generating a stable temperature field, exciting the thermocouple by the step temperature, collecting the response signal of the sensor and obtaining the time constant from response signal. The schematic diagram of the measurement system for time constant of the thermocouple based on high temperature furnace is shown in Figures 2 and 3 is the experimental setup. In the system, the stable temperature field is generated by the high temperature furnace, and the temperature in the furnace is controlled by the temperature controller. The fast feed device is used to realize the fast insertion, speed, and position control of the thermocouple in the high temperature furnace, and the thermocouple is mounted on the slider of the fast feed device. The thermocouple output terminal is connected to $0{ }^{\circ} \mathrm{C}$ thermostat by compensation wire. The output signal is collected and processed by amplifier and data acquisition device. The time constant of the thermocouple can be obtained by analyzing the thermocouple response signal.

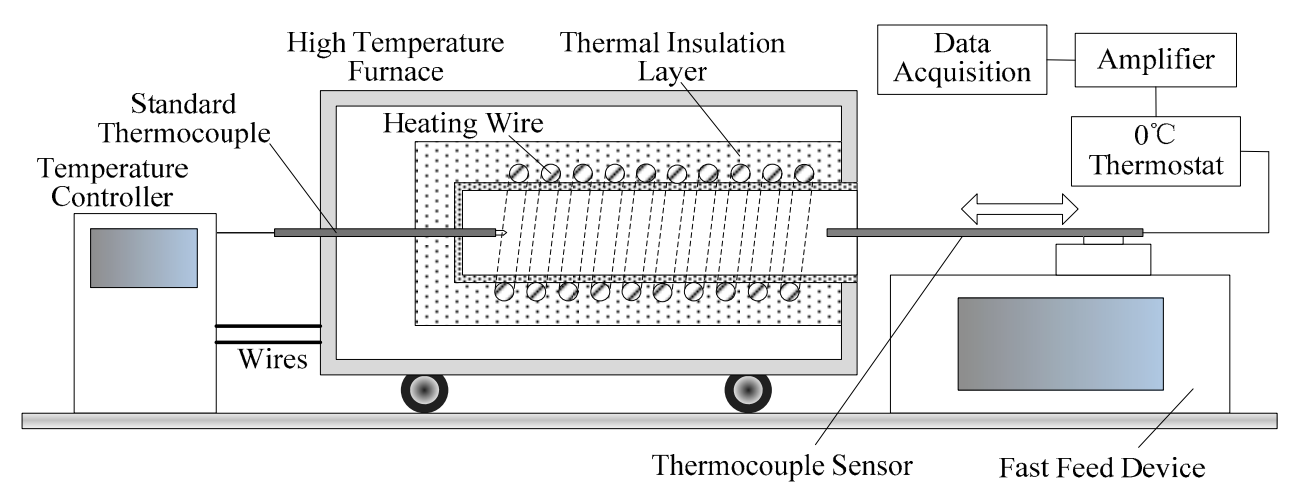

Figure 2. Measurement system for time constant of the thermocouple based on high temperature furnace.

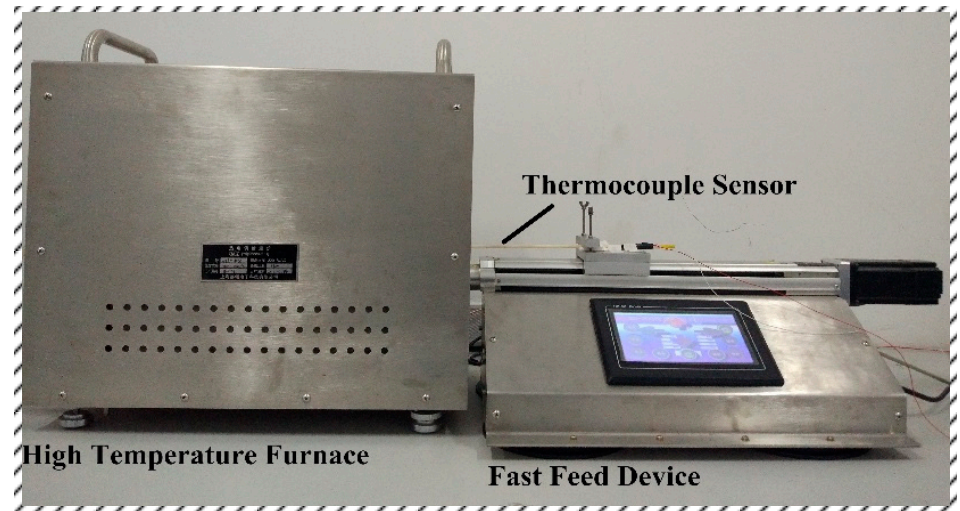

Figure 3. Experimental setup. 


\subsection{Generation of Ramp Temperature Excitation}

In the system, the inner diameter of the high temperature furnace is $20 \mathrm{~mm}$. At the distance of $120 \mathrm{~mm}$ from the furnace mouth, there is a uniform temperature zone with the thickness of $20 \mathrm{~mm}$, temperature error of $\pm 1{ }^{\circ} \mathrm{C}$ and temperature fluctuation of $\leq 0.2^{\circ} \mathrm{C} / \mathrm{min}$. The temperature of the uniform temperature zone can be set by the temperature controller, and the temperature range is from $300{ }^{\circ} \mathrm{C}$ to $1500{ }^{\circ} \mathrm{C}$. The high temperature furnace is heated by heating wire, and the heat insulation layer is made up of ceramic fiber blocks with low thermal conductivity. The temperature of the uniform temperature zone is measured by a standard thermocouple which is a second-class standard B-type thermocouple and has been verified by Shanghai Institute of Metrology. The output signal of the standard thermocouple is also fed back to the temperature controller which makes a high temperature furnace generate different temperatures through the PID control method.

In order to study the temperature distribution from the furnace mouth to the uniform temperature zone in the high temperature furnace, the standard thermocouple was used to measure the temperature at the distance of 10,20,40,60,80,100, and $120 \mathrm{~mm}$ respectively, as shown in Figure 4 . The thermocouple was moved by the fast feed device and accurately stays at different positions in the furnace. The temperature of the uniform temperature zone was $400{ }^{\circ} \mathrm{C}$, and the temperatures at different locations are shown in Figure 5. It can be seen from the figure that the temperature from the furnace mouth to the uniform temperature zone increases linearly. The temperature distributions from the furnace mouth to the uniform temperature zone were measured at different temperatures of uniform temperature zone. The experimental results show that when the temperature of uniform temperature zone is less than $700{ }^{\circ} \mathrm{C}$, the temperature profile from the furnace mouth to uniform temperature zone is linear or approximately linear. When the temperature is greater than $700{ }^{\circ} \mathrm{C}$, the temperature profile is not linear. However, the nonlinear distribution makes the measurement error of thermocouple time constant smaller. The research in this paper was carried out at the temperature of uniform temperature zone of between $300{ }^{\circ} \mathrm{C}$ and $700{ }^{\circ} \mathrm{C}$, and at this moment, the temperature distribution from the furnace mouth to the uniform temperature zone is linear.

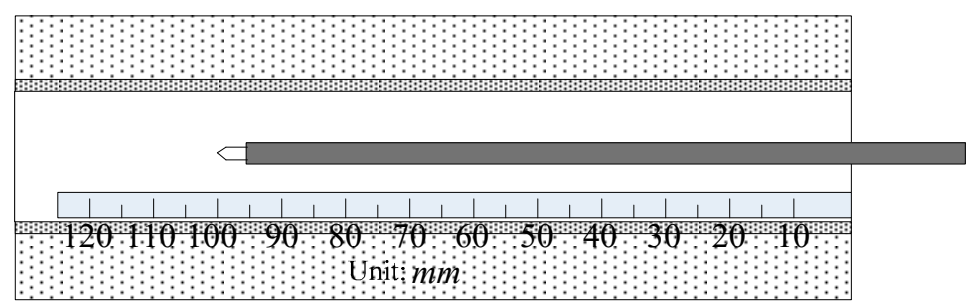

Figure 4. Schematic diagram of temperature measurement positions in high temperature furnace.

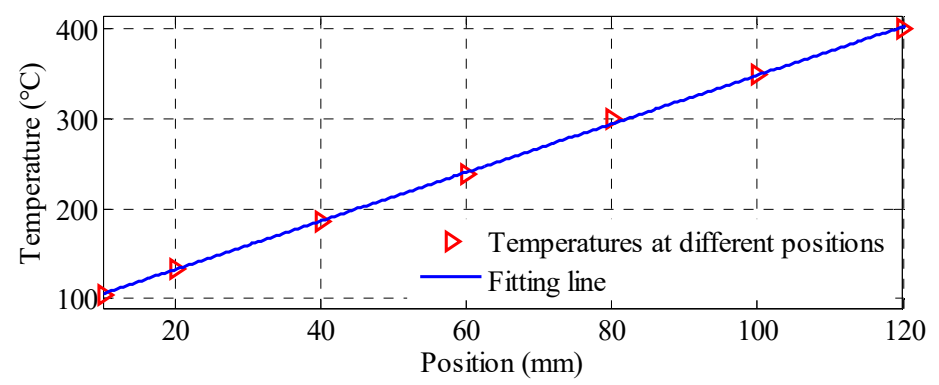

Figure 5. Temperatures at different positions.

In order to realize the rapid movement of the thermocouple, AC servo motor, screw, and slid block are used to build the fast feed device. The thermocouple is fixed on the slide block, and the screw drives the slide block to realize the movement of the thermocouple. AC servo motor has the advantages of high control precision, low frequency stability, resonance suppression, fast response speed and 
so on, and cooperating with the lead screw, it can realize the fast start-stop and fast movement of the thermocouple.

The thermocouple is quickly inserted into the uniform temperature zone from the furnace mouth by the fast feed device, and the temperature distribution in the furnace is linear, so the thermocouple is excited by the ramp temperature during the insertion process. In this system, the speed of the fast feed device can reach $300 \mathrm{~mm} / \mathrm{s}$, and the distance from the furnace mouth to the uniform temperature zone is $120 \mathrm{~mm}$. Therefore, the rise time of the ramp temperature excitation is $0.4 \mathrm{~s}$. According to Table 1 , when the measurement error of time constant is less than $5 \%$, this time constant measurement system can be used for time constant of the thermocouple whose time constant is larger than $4 \mathrm{~s}$.

\subsection{Analysis of Heat Transfer Environment in High Temperature Furnace}

In practical engineering, there are usually two or three heat transfer modes at the same time, which is called composite heat transfer. In the measurement system for time constant of the thermocouple based on high temperature furnace, the thermocouple is quickly inserted and stays in the uniform temperature zone at a distance of $120 \mathrm{~mm}$ from the furnace mouth, and the thermocouple is heated. There are three heat transfer modes: radiative heat transfer from furnace wall to the thermocouple, convective heat transfer from the gas to the thermocouple, and heat conduction from the surface of the thermocouple junction to the inside.

For bare thermocouple, the thermal resistance of heat conduction is very small relative to that of radiative and convection heat transfer in the heat transfer environment of high temperature furnace. The thermal resistance of heat conduction can be neglected, and it is considered that the temperature distribution inside the thermocouple junction is approximately uniform at any time. Therefore, the heat transfer modes between the thermocouple and the environment in the high temperature furnace are mainly radiative heat transfer and convective heat transfer. Because the heat transfer surface area of the thermocouple junction is much smaller than the inner wall area of the high temperature furnace, the quantity of radiation heat transfer can be expressed as

$$
\Phi_{r}=\varepsilon A \sigma\left[\left(T_{\omega} / 100\right)^{4}-(T / 100)^{4}\right],
$$

where $\varepsilon$ is the emissivity of the thermocouple, $A$ is the heat transfer area, $\sigma$ is the Steffan-Boltzmann constant, $T_{\omega}$ is the temperature of the furnace wall, and $T$ is the temperature of the thermocouple.

In order to analyze and calculate complex heat transfer problems, Equation (4) can be generally converted into a function of the surface heat transfer coefficient as

$$
\begin{gathered}
\Phi_{r}=h_{r} A\left(T_{\omega}-T\right), \\
h_{r}=\frac{\varepsilon \sigma\left[\left(T_{\omega} / 100\right)^{4}-(T / 100)^{4}\right]}{T_{\omega}-T},
\end{gathered}
$$

$h_{r}$ can be defined as surface heat transfer coefficient of radiative heat transfer. Assuming that $\varepsilon=0.4$, when the temperature of the furnace wall $T_{w}$ is constant, the surface heat transfer coefficients $h_{r}$ are obtained at different temperatures of the thermocouple, as shown in Figure 6. It can be seen from the figure that the surface heat transfer coefficient is related to the temperatures of the furnace wall and the thermocouple. When the temperature of the furnace wall $T_{w}$ is constant, $h_{r}$ increases with the increase of the temperature of the thermocouple. When the temperature of the thermocouple is constant, $h_{r}$ increases with the increase of the temperature of the furnace wall $T_{w}$. 


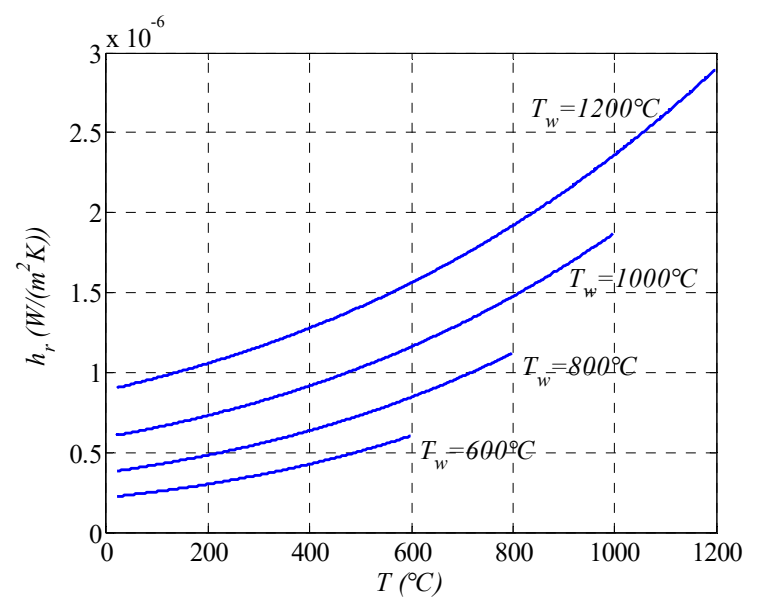

Figure 6. Relationship between surface heat transfer coefficient and temperature.

For convection heat transfer, according to Newton's law of cooling, the quantity of convection heat transfer can be expressed as

$$
\Phi_{c}=h_{c} A\left(T_{g}-T\right),
$$

where $h_{c}$ is the convective heat transfer coefficient, $A$ is the convective heat transfer area which is approximately equal to the radiative heat transfer area, and $T_{g}$ is the temperature of the gas around the thermocouple.

In the high temperature furnace, the total quantity of heat transfer of the thermocouple can be expressed as the sum of the quantity of radiative heat transfer and convection heat transfer. Assuming that the wall temperature is equal to the gas temperature in any section of the furnace chamber, i.e., $T_{\omega}=T_{g}$, the total quantity of heat transfer of the thermocouple can be expressed as

$$
\Phi=\Phi_{r}+\Phi_{c}=A\left(h_{r}+h_{c}\right)\left(T_{g}-T\right) .
$$

Assuming that the temperature distribution of each part of the cross-section of the thermocouple is uniform, the temperature decreases along the axis, and the heat flux transferred along the axis can be expressed as

$$
d q_{c d}=k f \frac{d T}{d l}
$$

where $k$ is thermal conductivity, $f$ is the cross-section area, and $d l$ is the length of the heat flow transferred along the axis.

When the thermocouple reaches the heat balance, the heat quantity transferred from the inner wall of the high temperature furnace and the gas to the thermocouple is equal to the heat quantity dissipated by the thermocouple along the axis by the heat conduction, that is

$$
A\left(h_{r}+h_{c}\right)\left(T_{g}-T\right)=k f \frac{d T}{d l} .
$$

Therefore, the heat conduction error caused by the temperature gradient along the axis of the thermocouple can be obtained

$$
\Delta T_{c d}=T_{g}-T=\frac{k f}{A\left(h_{r}+h_{c}\right) L}\left(T-T_{b}\right),
$$

where $L$ is the insertion depth of the thermocouple, and $T_{b}$ is the temperature at the furnace mouth.

It can be seen from Equation (11) that in order to reduce the heat conduction error, the depth of the thermocouple inserted into the high temperature furnace should be increased as much as possible. For bare thermocouples, when the ratio of insertion depth $L$ to the diameter $d$ of the thermocouple 
is $L / d \geq 10$, a higher measurement accuracy can be obtained. For the case of the temperature measurement of gas flow with low Reynolds number or higher measurement accuracy, the ratio should be $L / d \geq 20 \sim 50$. In the time constant measurement system, the insertion depth of thermocouple sensor is $120 \mathrm{~mm}$, and the diameter of thermocouple is generally several millimeters, so the heat conduction error can be neglected.

\section{Experiment}

The time constant of a K-type thermocouple wire with the diameter of $0.5 \mathrm{~mm}$ was measured by the measurement system for time constant of the thermocouple based on high temperature furnace. Two electrodes of the thermocouple are welded by spherical welding to form the junction whose diameter is $1 \mathrm{~mm}$. The thermocouple wire was installed in the high temperature ceramic sleeve, as shown in Figure 7. In the radiative heat transfer mode, the time constant of the thermocouple is the function of temperature and is related to the temperature of the object to be measured. Therefore, the time constants of the thermocouple measured at different furnace temperatures are different. The temperatures of uniform temperature zone in high temperature furnace were set to 300, 400, 500, 600 , and $700{ }^{\circ} \mathrm{C}$ respectively. According to the definition of time constant and the output signals of the thermocouple, the time constants are $101.993,87.355,73.672,60.258$, and 48.819 s respectively. The output curves are shown in Figure 8.

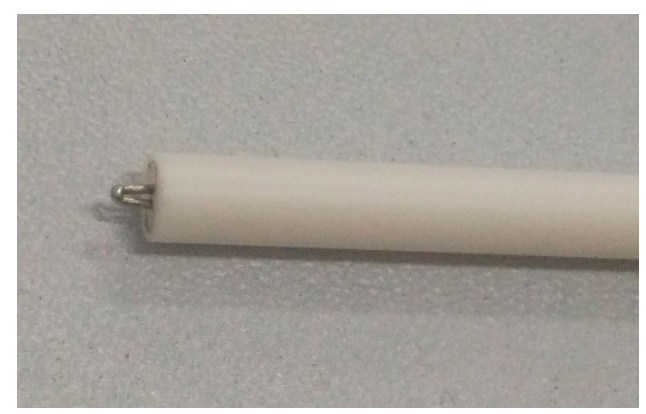

Figure 7. K-type thermocouple wire.

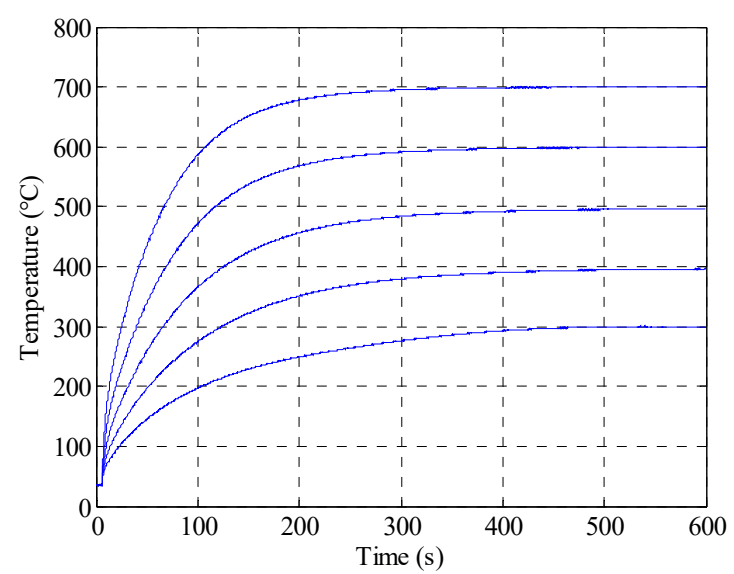

Figure 8. Output signals of the thermocouple at different furnace temperatures.

Five independent repeated experiments for the thermocouple were carried out at the uniform temperature zone temperature of $380^{\circ} \mathrm{C}$. The output signals of the thermocouple are shown in Figure 9 , and the time constants are shown in Table 2. The best estimate of the time constant of the thermocouple is the average of five estimates, that is

$$
\bar{\tau}=\frac{1}{n} \sum_{i=1}^{n} \tau_{i}=87.7566 s
$$




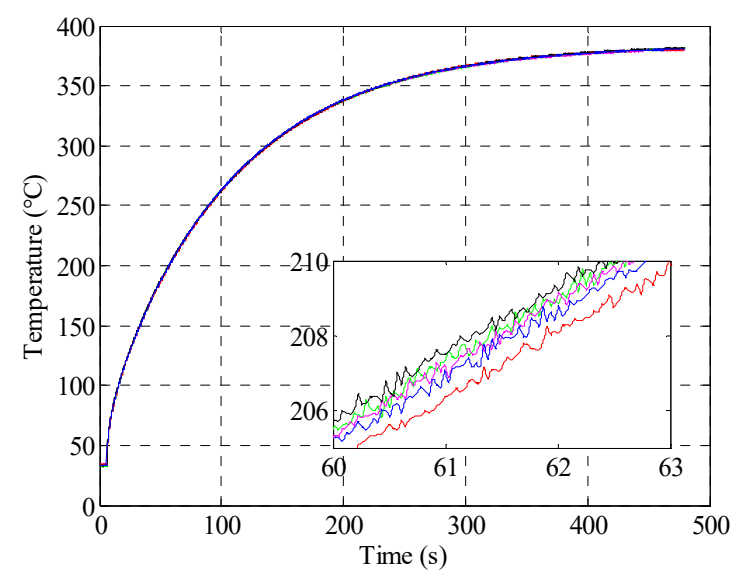

Figure 9. Output signals of the thermocouple.

Table 2. Time constant estimates

\begin{tabular}{cccc}
\hline $\boldsymbol{n}$ & Time Constant (s) & $\boldsymbol{n}$ & Time Constant (s) \\
\hline 1 & 87.7232 & 4 & 87.2350 \\
2 & 87.6740 & 5 & 87.9329 \\
3 & 88.2180 & & \\
\hline
\end{tabular}

\subsection{Analysis of Type A Standard Uncertainty}

When the number of independent repeated experiments is large, the experimental standard deviation of the measured value can be calculated according to Bessel's formula, and when the number of experiments is small, the extreme difference method can be used. In the measurement experiment of time constant, the time constant of the thermocouple was measured five times, so the standard deviation which indicates the dispersion of the time constant estimates was calculated by the extreme difference method. The extreme difference coefficients $C$ and degrees of freedom $v$ are shown in Table 3 , and the experimental standard deviation $s\left(\tau_{k}\right)$ of time constant is

$$
s\left(\tau_{k}\right)=\frac{R}{C}=\frac{0.9830}{2.33} s=0.4219 s .
$$

Table 3. Extreme difference coefficients and degrees of freedom

\begin{tabular}{ccccccccc}
\hline $\boldsymbol{n}$ & $\mathbf{2}$ & $\mathbf{3}$ & $\mathbf{4}$ & $\mathbf{5}$ & $\mathbf{6}$ & $\mathbf{7}$ & $\mathbf{8}$ & $\mathbf{9}$ \\
\hline$C$ & 1.13 & 1.69 & 2.06 & 2.33 & 2.53 & 2.70 & 2.85 & 2.97 \\
$v$ & 0.9 & 1.8 & 2.7 & 3.6 & 4.5 & 5.3 & 6.0 & 6.8 \\
\hline
\end{tabular}

The Type A standard uncertainty of time constant estimate is as shown in Equation (14), and the degrees of freedom is 3.6.

$$
u_{A}=s(\bar{\tau})=s\left(\tau_{k}\right) / \sqrt{n}=0.1887 s .
$$

\subsection{Analysis of Type B Standard Uncertainty}

Sampling interval of data acquisition device produces Type B uncertainty component. Because the time constant obtained from the response signal is the difference between the start time and the time corresponding to the $63.2 \%$ final temperature value, the estimate value of the time constant is uniformly distributed in the interval $[\bar{\tau}-\Delta t, \bar{\tau}+\Delta t]$. The sampling frequency of the acquisition device was $500 \mathrm{~Hz}$, so Type B uncertainty of the time constant estimate is

$$
u_{B 1}=\frac{\Delta t}{k}=\frac{0.002}{\sqrt{3}} s=0.0012 s,
$$


where $k$ is confidence factor. When the data is uniformly distributed in the interval, $k=\sqrt{3}$.

The thermocouple time constant in the radiative heat transfer mode is related to the temperature of the high temperature furnace, so the temperature error of the furnace will also produce uncertainty for time constant measurement. The temperature of the uniform temperature zone of high temperature furnace was set to vary from $300{ }^{\circ} \mathrm{C}$ to $700{ }^{\circ} \mathrm{C}$. The time constant of the thermocouple was measured every $50{ }^{\circ} \mathrm{C}$. The time constants at different temperatures are shown in Table 4 . The curve of time constant and the temperature of high temperature furnace was fitted, as shown in Figure 10, the polynomial of the curve is

$$
f(T)=4.991 \times 10^{-5} T^{2}-0.1838 T+152.8 .
$$

Table 4. Time constants at different temperatures

\begin{tabular}{cccc}
\hline Temperature $\left({ }^{\circ} \mathbf{C}\right)$ & Time Constant (s) & Temperature $\left({ }^{\circ} \mathbf{C}\right)$ & Time Constant (s) \\
\hline 300 & 101.993 & 550 & 66.88 \\
350 & 94.909 & 600 & 60.258 \\
400 & 87.355 & 650 & 54.387 \\
450 & 80.071 & 700 & 48.819 \\
500 & 73.672 & & \\
\hline
\end{tabular}

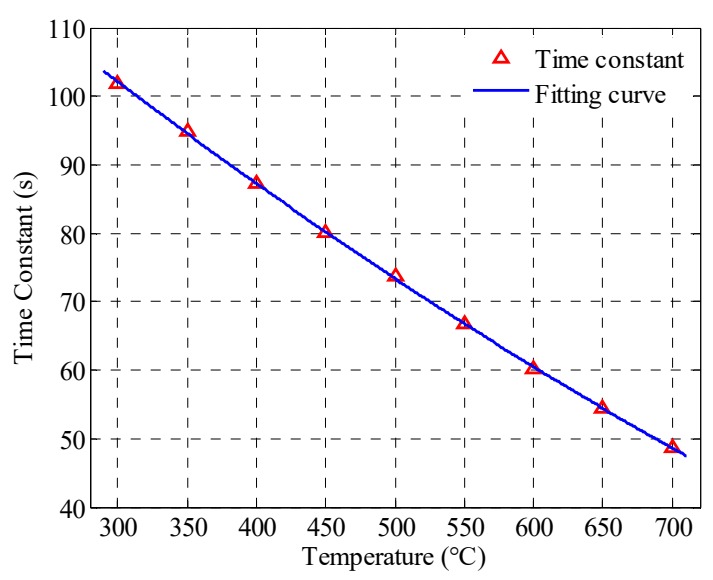

Figure 10. Curve of time constant and the temperature of high temperature furnace.

Therefore, the temperature sensitivity coefficient of the time constant can be obtained as

$$
\frac{\partial f(t)}{\partial T}=9.982 \times 10^{-5} T-0.1838,
$$

where $T$ is the temperature of the uniform temperature zone of high temperature furnace, and $f(t)$ is the equation of time constant, $\tau=f(t)$.

The temperature error of the uniform temperature zone of high temperature furnace is $\pm 1^{\circ} \mathrm{C}$, and the temperature is uniformly distributed in the interval $T \pm 1^{\circ} \mathrm{C}$. So the uncertainty is

$$
u(T)=\Delta T / k=0.58
$$

Therefore, the Type B uncertainty component of time constant produced by the temperature error of the uniform temperature zone is

$$
u_{B 2}=\left|\frac{\partial f(t)}{\partial T} u(T)\right|=0.0846 s .
$$




\subsection{Combined Standard Uncertainty and Expanded Uncertainty}

According to the above analysis, the components of the measurement uncertainty of the thermocouple time constant are independent of each other, and the combined standard uncertainty is obtained by

$$
u_{c}=\sqrt{u_{A}^{2}+u_{B 1}^{2}+u_{B 2}^{2}}=0.2068 s .
$$

In summary, when the temperature of the uniform temperature zone of high temperature furnace is $380^{\circ} \mathrm{C}$, the best estimate of the thermocouple time constant $\tau=87.7566 \mathrm{~s}$, the combined standard uncertainty $u_{c}=0.2068 \mathrm{~s}$, and When the inclusion probability of the determined interval is $95 \%$, the expanded uncertainty $U=k u_{c}=0.4136 s, k=2$.

\section{Conclusions}

The time constant of the thermocouple sensor reflects its response speed in dynamic temperature measurement and is an important performance parameter. Depending on different heat transfer modes, there are various methods and systems for measuring the time constant. In this paper, the measurement system was constructed by using a high temperature furnace to produce a stable temperature field. When the temperature of the uniform temperature zone is within $300-700^{\circ} \mathrm{C}$, the temperature profile from the furnace mouth to uniform temperature zone is linear. In the system, a fast feed device was used to insert the thermocouple into the high temperature furnace and generate the ramp temperature excitation. Compared with other measurement systems for measuring time constant, the developed system in this paper has many advantages. Compared with the shock tube, the steady state excitation temperature produced by high temperature furnace is stable and can last for a longer time. Compared with the hot wind tunnel, the constant temperature field with stable temperature can be generated, and the fast feed device can enable the thermocouple inserted into the temperature field at different speeds. In addition, high temperature furnace can produce thermal field of higher temperature.

Because of the close relationship between the thermocouple time constant and heat transfer mode, if the time constant measured in the laboratory is of guiding significance to practical application, the measurement environment in the laboratory should be consistent with or similar to the actual application environment. Therefore, an appropriate measurement method and system should be selected according to the actual application environment. In the measurement system developed in this paper, the fact that the main heat transfer mode of the thermocouple is radiative heat transfer makes it suitable for applications for kiln or boiler. In addition, some scholars have also studied the on-site measurement method of the thermocouple time constant.

Author Contributions: Conceptualization, Z.Z. and Y.L.; Methodology, Z.Z.; Validation, Y.L. and Z.Z.; Writing—original draft preparation, Y.L.; Writing—review and editing, Z.Z. and W.Y.; Supervision, X.H.; Project administration, Z.Z.

Funding: This research was funded by National Natural Science Foundation of China, grant number 51575499, 61473267 and sponsored by the Fund for Shanxi "1331 Project" Key Subject Construction.

Conflicts of Interest: The authors declare no conflict of interest. The funders had no role in the design of the study; in the collection, analyses, or interpretation of data; in the writing of the manuscript, or in the decision to publish the results.

\section{References}

1. Xiong, J.; Yu, H.Z. Response Delay of Thermal Sensors. J. Electron. Meas. Instrum. 2003, 17, 1-3.

2. Wang, X.N.; Yu, F.Z.; Yang, S.J;; Qi, M.Y.; Ye, S.L. Study of TFTC Dynamic Character Based on Lumped Capacitance Method. Chin. J. Sens. Actuators 2014, 27, 1627-1631.

3. Zhao, S.A.; Liao, L.; Chen, Y. $1700{ }^{\circ} \mathrm{C}$ Hot Wind Tunnel for Thermal Calibration. Metrol. Meas. Technol. 2000, 20, 3-6.

4. Yang, Z.X.; Meng, X.F. Research on the Dynamic Calibration of Thermocouple and Temperature Excitation Signal Generation Method Based on Shock-Tube Theory. J. Eng. Gas Turb. Power 2014, 136, 071602. [CrossRef] 
5. Yang, Z.X.; Meng, X.F. Study on Transient Temperature Generator and Dynamic Compensation Technology. Appl. Mech. Mater. 2014, 2, 161-164. [CrossRef]

6. Garinei, A.; Tagliaferri, E. A laser calibration system for in situ dynamic characterization of temperature sensors. Sens. Actuators A-Phys. 2013, 190, 19-24. [CrossRef]

7. Serio, B.; Nika, P.; Prenel, J.P. Static and dynamic calibration of thin-film thermocouples by means of a laser modulation technique. Rev. Sci. Instrum. 2000, 71, 4306-4313. [CrossRef]

8. Arwatz, G.; Bahri, C.; Smits, A.J.; Hultmark, M. Dynamic calibration and modeling of a cold wire for temperature measurement. Meas. Sci. Technol. 2013, 24, 125301. [CrossRef]

9. Hao, X.J.; Li, K.J.; Liu, J.; Zhou, H.-C.; Huang, L. Traceability Dynamic Calibration of Temperature Sensor Based on $\mathrm{CO}_{2}$ Laser. Acta Armamentarii 2009, 30, 156-159.

10. Feng, H.; Zhao, C.Y.; Xie, Y.N.; Wang, W.L.; Zhang, X.; Zhang, Z.J. Research on dynamic calibration and dynamic compensation of K-type thermocouple. In Proceedings of the 2014 IEEE International Instrumentation and Measurement Technology Conference (I2MTC) Proceedings, Montevideo, Uruguay, 12-15 May 2014; pp. 267-271.

11. Castellini, P.; Rossi, G.L. Dynamic characterization of temperature sensors by laser excitation. Rev. Sci. Instrum. 1996, 67, 2595-2601. [CrossRef]

12. Hashemian, H.M.; Jiang, J. Using the noise analysis technique to detect response time problems in the sensing lines of nuclear plant pressure transmitters. Prog. Nucl. Energy 2010, 52, 367-373. [CrossRef]

13. Al-Dawery, S.K.; Alrahawi, A.M.; Al-Zobai, K.M. Dynamic modeling and control of plate heat exchanger. Int. J. Heat Mass Tran. 2009, 55, 6873-6880. [CrossRef]

14. Tashiro, Y.; Biwa, T.; Yazaki, T. Calibration of a thermocouple for measurement of oscillating temperature. Rev. Sci. Instrum. 2005, 76, 124901. [CrossRef]

15. Kim, S.J.; Park, G.C. Development of algorithm to measure temperatures of liquid/gas phases using micro-thermocouple and experiment with optical chopper. J. Mech. Sci. Technol. 2007, 21, 184-195. [CrossRef]

16. Zhang, Z.J.; Li, Y.F. A dynamic calibration system of thermocouple sensor based on high temperature furnace. In Proceedings of the IEEE International Instrumentation and Measurement Technology Conference (I2MTC): Discovering New Horizons in Instrumentation and Measurement, Proceedings, Houston, TX, USA, 14-17 May 2018; pp. 1-5.

(C) 2018 by the authors. Licensee MDPI, Basel, Switzerland. This article is an open access article distributed under the terms and conditions of the Creative Commons Attribution (CC BY) license (http:/ / creativecommons.org/licenses/by/4.0/). 